\title{
28 Research Suare \\ Maternity Waiting Home and Maternal Mortality Ratio in EI Salvador
}

\section{Heesang Yoon ( $\square$ viva826@snjc.ac.kr)}

Nursing Department, Seoul Women's College of Nursing, 38 Ganhodae-ro, Seodaemun-gu, Seoul, Korea

Chong-sup Kim

Seoul National University Graduate School of International Studies

\section{Research}

Keywords: Maternal mortality ratio, Maternity waiting home, El Salvador

Posted Date: August 25th, 2020

DOI: https://doi.org/10.21203/rs.3.rs-58848/v1

License: (-) (1) This work is licensed under a Creative Commons Attribution 4.0 International License. Read Full License 


\section{Abstract}

Background: El Salvador is recognized as a country which could effectively reduce the maternal mortality ratio (MMR). In El Salvador, there was an improvement in health indicators, such as fertility rate, adolescent fertility rate, skilled birth attendance, health expenditures, but this improvement was not extraordinary compared with other developing countries. The reason El Salvador could achieve an outstanding decrease in MMR in spite of a not so special improvement in health or non-health indicators, deserves a deep research.

Methods: We used quantitative as well as qualitative methods to show that the reason El Salvador could reduce maternal mortality ratio more than expected is the health policy that not only aimed at reducing the (adolescent) fertility rate, but also provided a safe birth service to pregnant women through maternity waiting home. As quantitative methods we ran regressions using maternal mortality ratio as dependent variable, health and non-health factors as independent variables. As qualitative methods, we carried out a case study of maternal waiting home in El Salvador.

Results: El Salvador could reduce maternal mortality ratio through the improvement of health factors, such as fertility rate, skilled birth attendance, and non-health factors, such as GDP per capita and woman empowerment. However, even considering these factors, maternal mortality ratio of El Salvador decreased more than expected. We confirmed this by analyzing the residuals of the regression model. This improvement in MMR, which is more than expected from the regression results, can be attributed partly to the government measures, such as maternity waiting home.

Conclusions: The reason of the unexplained reduction in El Salvador's maternal mortality ratio seems to be attributable to the health policy that not only aimed at reducing the fertility rate, but also provided a safe birth service to pregnant women through maternity waiting home.

\section{Plain English Summary}

El Salvador is recognized as a country which could effectively reduce the maternal mortality, which means the death of a woman while pregnant or within 42 days of termination of pregnancy. Maternal mortality ratio (MMR) in El Salvador decreased from 118 per 100,000 live births in 1995 to 54 in 2015, which means a reduction of $54.2 \%$. This was the largest reduction among comparable Latin American countries.

This reduction is explained partly by the improvement of socio-economic conditions in El Salvador, such as GDP per capita, access to electricity, education level, etc. Other factors that also contributed to the reduction of maternal mortality are the improvement of health conditions, such as lower fertility rate, especially lower adolescent fertility rate, skilled birth attendance, and health expenditures. However, all these improvements were not so different from other developing countries as to explain the huge improvement in El Salvador with regard to maternal mortality. Then, what is the reason of the extraordinary decrease of maternal mortality in El Salvador?

This study analyzed the reason El Salvador could achieve an outstanding decrease in maternal mortality in spite of a not so special improvement in health or non-health indicators.

We contend that the reason El Salvador could reduce maternal mortality ration more than expected is the health policy that not only aimed at reducing the (adolescent) fertility rate, but also provided a safe birth service to pregnant women through Family Health Community Teams and maternity waiting home. One of the tasks of Family Health Community Teams was encouraging women and their families in remote areas to take necessary steps to give birth at the hospital. On the other hand, the objective of maternity waiting home was accommodating expectant mothers that are spread out over remote mountain areas to clinics, so that they could rest in proximity areas until due dates when they would be 
transported to nearby hospitals for the delivery. The number of users of maternity waiting home in 2013 was over 2,500 , which is over $70 \%$ of the expectant mothers that needed this service.

Many adolescents used maternity waiting home, as we can know from the fact that the percentage of adolescents among the pregnant women using this facility was $35 \%$. So, we can conclude that El Salvador was not so successful in preventing the adolescents from getting pregnant but was more successful in preventing the deaths of the adolescents during or after the delivery of the baby.

The reduction of deaths of adolescents related with the delivery of the baby thanks to Family Health Community Teams and maternity waiting home, explains most of the unexplained part of the reduction in El Salvador's maternal mortality ratio.

\section{Background}

El Salvador is recognized as a country which could effectively reduce the maternal mortality ratio (MMR). There was an improvement in health indicators, such as fertility rate, adolescent fertility rate, skilled birth attendance, health expenditures, but this improvement was not extraordinary compared with other developing countries. The reason El Salvador could achieve an outstanding decrease in MMR in spite of a not so special improvement in health or nonhealth indicators, deserves a deep research. Our hypothesis is that the main cause was the health policy that not only aimed at reducing the (adolescent) fertility rate, but also provided a safe birth service to pregnant women, for example through maternity waiting home.

In this paper we first explain the evolution of maternal mortality ratio in El Salvador, together with other health indicators. In the second section, we build an empirical model to explain the differences of maternal mortality ratios across countries, and based on this model show that the case of El Salvador cannot be fully explained with the health and non-health indicators traditionally used in the analysis of maternal mortality ratio. In the third section, we suggest that maternity home program was an important factor that explains the large drop of maternal mortality ratio in El Salvador.

\section{Method}

\section{Maternal mortality in El Salvador}

MDG Report states that the MMR in El Salvador has been considerably reduced in the 1990s and 2000s and that this trend would continue [1]. El Salvador has met with MDG targets regarding maternal mortality ratio. According to the data from World Development Indicators [2], as shown in Table 1, maternal mortality index in El Salvador decreased from 118 per 100,000 live births in 1995 to 54 in 2015, which means a reduction of $54.2 \%$. This was the largest reduction among comparable Latin American countries. The average MMR of Latin American countries decreased from 118 in 1995 to 68 in 2015, a 47.2\% reduction.

However, in spite of an outstanding reduction of MMR, other health indicators did not improve on the same scale. Total fertility rate in El Salvador declined from 3.58 in 1995 to 2.10 in 2015, which is not so remarkable compared with other Latin American countries. The reduction of adolescent fertility ratio was the lowest after Ecuador among comparable countries in Table 1. As for non-health indicators, health expenditure to GDP ratio was reduced by 0.9 percentage points whereas it increased in most of the other Latin American countries.

These trends are very strange if we consider that the health factors, such as fertility rate, adolescent fertility rate, and health expenditure, are important determinants of MMR. If these factors improve we would expect an improvement in 
the MMR. Naturally, with an outstanding improvement in MMR, we would expect an improvement of these factors at an equal scale. In El Salvador, this did not happen: an outstanding improvement in MMR was accompanied by a moderate improvement of health indicators and a decrease in health expenditure.

\section{An empirical model of MMR}

To confirm that MMR in El Salvador has declined more than expected from the improvement of health indicators as well as non-health indicators, we built an empirical model employing MMR as dependent variable, and health and nonhealth indicators as independent variables.

The regression model is as follows:

$$
\begin{aligned}
\log (M M R)= & \alpha+\beta_{1} \log (\text { TFR })+\beta_{2} \log (\text { ATFR })+\beta_{3} \log (\text { SKILL })+\beta_{4} \log (\text { HEALTH }) \\
& +\beta_{5} \log (\text { GDPC })+\beta_{6} \log (\text { FSENCOND })+\beta_{7} \log (\text { ELECTRIC }) \\
& +\beta_{8} \log (\text { URBAN })+\beta_{9} \log (\text { FPARTICI })+\beta_{10} \log (\text { FPARLIA })
\end{aligned}
$$

The dependent variable is maternal mortality rate, and the independent variables are both health sector variables and non-health sector variables. The variables included in the model are explained in Table 2. The data used in the regression were country level annual data from 2000 to 2015.

\section{Data analysis methods}

We ran three regressions: Pooled OLS model, Fixed and Random Effect Panel Regression models. The data used in this study are from World Development Indicators (WDI), which provides cross country comparable data on development. The number of countries included in the analysis was 143, and the years of analysis was from 2000 to 2015 [2].

\section{Results}

In pooled OLS model, most of the coefficients have the right sign and are significant (Table 3). Among health sector indicators, if total fertility rate decreases by $1 \%$, MMR would decrease by $0.97 \%$. If the adolescent fertility rate decreases by $1 \%$, MMR would decrease by $0.49 \%$. If skilled birth attendance or health expenditure increases, MMR would decrease. Among the non-health sector indicators, GDP per capita seems to be the most important. If GDP per capita increases by $1 \%$, MMR would decrease by $0.30 \%$. The improvements of female secondary school enrollment, access to electricity, and women empowerment also have positive effect on the reduction of MMR with different level of significance.

Panel regressions with random effect and fixed effect give similar results (Table 3). In the panel regression with fixed effect, that controls time-invariant heterogeneity of the countries, even if total fertility rate loses significance, adolescent fertility rate still is significant and the coefficient has similar value as in the pooled OLS. Skilled birth attendance has the right sign and is significant. Among the non-health sector indicators, GDP per capita is the only one that is significant. Overall, the most important variable that explains the change in MMR seems to be adolescent fertility rate.

The importance of adolescent fertility rate was pointed out by many researches. According to UNFPA [3] and WHO and UNFPA [4], adolescents with age of 15 through 19 are twice as likely to die during pregnancy or child birth as those over age 20; girls under age 15 are five times more likely to die.

To analyse the case of El Salvador, we calculated the predicted value of El Salvador based on the fixed effect panel regression model and compared it with the observed value. In the Figure 1, prediction without fixed effect is the 
predicted value of MMR considering the value of the independent variables but not taking into account the fixed effect. This predicted value is much higher than the observed value. Prediction without fixed effect decreases as the variables such as adolescent fertility rate, skilled birth attendance, GDP per capita in El Salvador improved during the period of analysis. However, this does not consider that there may be unobserved time invariant characteristics of El Salvador. Even fully considering the independent variables, El Salvador had consistently lower MMR than expected. If the negative fixed effect is included, the predicted value is lower, as shown by prediction including fixed effect in the Figure 1. This negative fixed effect may be attributed to an efficient health care system in El Salvador, which is not reflected in the independent variables.

From the graph, we can also observe that the observed value decreased more rapidly than the prediction with fixed effect, resulting in increased residuals. Actually, this cannot be explained by either independent variables or fixed effect. It must be explained by some other changes in policies or health system in El Salvador during this period, which are not reflected in the independent variables. Although there were large drops in MMR in 2002, 2007 and 2008, we would like to focus on the decline after 2011(Figure 1).

In the Table 4, the predicted MMR decreased by 3 between 2011 and 2013. However, the observed MMR decreased by 5 during the same period. This means that a reduction of 2 must be explained by something else than the independent variables.

\section{Discussion}

One of the most important variables that explain the change in the maternal mortality rate is adolescent fertility rate. However, in El Salvador MMR decreased more than expected from the reduction of adolescent fertility rate, as this did not decrease that much compared to the countries in similar situation, as can be noticed from the Table 1. How this happened?

The reason is that El Salvador was not so successful in preventing the adolescents from getting pregnant but was more successful in preventing the deaths of the adolescents during or after the delivery of the baby. We suggest that this partial success can be explained by Family Health Community Teams (Unidades Comunitarias de Salud Familiar: UCSF) and maternity waiting home.

The $3^{\text {rd }}$ report on the Progress of the Millennium Development Goals of El Salvador states:

Non-hospital maternal mortality, in particular, has been occurring with decreasing frequency. Healthcare representatives and more recently, Family Health Community Teams successfully managed to implement the Birth Plan strategy, mainly in rural communities, with the primary purpose of encouraging women and their families to take any necessary steps to give birth at the hospital. This has made it possible today for more than $90 \%$ of births to take place in hospitals, mainly belonging to the public network and the Salvadoran Institute of Social Insurance.

Considering the level of economic development, El Salvador has relatively well-established health care system, especially for the primary health care $[5,6]$. At the level of municipal health networks, UCSF health centres are in charge of primary medical services [7]. Nationwide, there are more than 360 UCSF that are in charge of health promotion,

prevention, treatment and rehabilitation [7,8]. Medical team that work in UCSF is called ECOS (Community Health Team: Equipos Comunitarios de Salud), and consists of doctors, nurses, nutritionists, health education specialists, psychology counselors, and nurse assistants [9]. ECOS provides primary care on checkup, treatment, vaccination, and medicine provision [10]. Local community health personnel in UCSF health centres are trained for a certain period of time and placed in UCSF to learn, research, and routinely report health problems of the designated region. Furthermore, they are 
to keep track of conditions of expectant mothers in mother and child health related issues and report it to health centres [11]. One local community health worker is required to attend 200 households residing in the region [7].

In 2009, to strengthen primary medical services and prevent exclusion of remote residents [12], especially pregnant women, the government of El Salvador established a program of Maternity Waiting Home for Expectant Mothers (Hogar de Espera Materna: HEM). With assistance from international community, 16 HEMs were set up by 2013[1]. The objective of HEM was to induce expectant mothers that are spread out over remote mountain areas to clinics, so that they could rest in proximity areas until due dates when they would be transported to nearby hospitals for the delivery $[12,13]$. Therefore, HEM in El Salvador is located with UCSF or nearby health centres so that patients can be requested to be transferred to connected hospitals that are equipped with childbirth delivery facilities. Expectant mothers reside in and wait for their due dates in HEM health clinics near their resident homes [7,12]. At impending delivery, expectant mothers and their treatment records from respective HEM can both be transferred to hospitals via UCSF vehicles, ambulances, or taxis.

When distance between residence and hospitals are too far or hospital visits are geographically difficult, expectant mothers can come a day early and stay at HEM until their hospital check-up and can return home after receiving treatment $[7,14,15]$. After delivery, mothers can also come a day early to stay at HEM before giving vaccinations to newborn babies the next day. Furthermore, HEM health clinics act as safe havens for expectant mothers and newborn babies facing social risks. Fees to use HEM are all free of charge. During expectant mothers' stay at HEM, they are provided with housing and meals that are particularly essential during pregnancy. After delivery, mothers that want support are provided with clothing for their newborn babies $[7,13]$.

At the HEM, licensed specialists in mother and child health reside on-site 24 hours and manage health conditions of both expectant mother and fetus by checking on the health of expectant mothers and listening to cardiac sounds of the fetus twice a day. Functions of HEM are to provide facilities for at high-risk expectant mothers and newborn babies and to strengthen geographical accessibility. Either nearby or situated together with UCSF, the clinic provides health education for reproductive health and childbirth delivery [12]. As expectant mothers who enter HEM mostly reside in regions that have difficult accessibility and transportation to hospitals, the health clinic estimates around $40 \%$ of the nearby regions' expectant mothers to be its target population [7]. For all other expectant mothers in the region, it seems that although they may reside in remote areas they have access to means of transport to hospitals for delivery and do not need to enter HEMs. Entrance into HEMs takes place through recommendations from local community health personnel, UCSF, or other expectant mothers who have previously experienced the clinics. The majority of expectant mothers get into clinics around 2-3 days before delivery. Although mothers voluntarily come to clinics, for those without transportation and with difficulty reaching the clinic, UCSF provides vehicles for transportation.

In 2013, the total number of users of HEM was 2,587, as shown in Table 5. Among them, 913 users were adolescents. The percentage of adolescents among the pregnant women who used HME was $35 \%$. This extremely high proportion of adolescent users may be explained by the high adolescent pregnancy in the remote rural areas [16], by the high reliance of adolescent on this facility, and by the efficient work of UCSF in guiding the pregnant adolescents to the HEM.

In 2013, expectant mothers' average use of HEM throughout seven HEM was around $70 \%$, which is close to the Department of Health's goal of $80 \%$ coverage. El Salvador's mountainous geography makes transportation difficult and medical facility accessibility challenging in many regions; various conditions such as transportation are not readily supported in El Salvador particularly in case of expectant mothers in remote areas that rapidly try to access hospitals at impending stages before delivery. HEMs were constructed to target expectant mothers from such remote areas so that they could be attracted to better utilize medical facilities and have facility deliveries. It appears that the project has positively influenced the region in increasing facility-based deliveries and reducing maternal and child mortality rates. It 
is expected that many users would have given home childbirth without HEM, which was confirmed by fieldwork interviews with expectant mothers using HEM.

It is obvious that the system of UCSF and HEM has reduced MMR by inducing vulnerable expectant mothers to the hospitals and enabling facility-based delivery. As the most important group of vulnerable expectant mothers are adolescents [17], this system inarguably reduced the number of adolescent deaths related to the maternity. However, the system was not so successful in reducing the pregnancy of adolescents. Adolescent were given education about sex and maternity once they were pregnant and hosted in HEM, not before getting pregnant. Of course, there was sexual education in the schools, but this was not so effective in reducing the adolescent pregnancy $[16,17]$.

\section{Conclusion}

We have shown that El Salvador could reduce MMR through the improvement of health factors, such as fertility rate, adolescent fertility rate, skilled birth attendance, etc., and non-health factors, such as GDP per capita and woman empowerment. However, even considering these factors, maternal mortality ratio of El Salvador decreased more than expected. We confirmed this by analyzing the residuals of a regression model. The reason of this unexplained reduction of El Salvador's MMR seems to be attributable to the health policy that not only aimed at reducing the (adolescent) fertility rate, but also provided a safe birth service to pregnant women, for example through Maternity Waiting Home. Nevertheless, as the adolescent fertility rate is still too high and pregnancy in adolescents continues to be an important cause of maternal deaths, more effective policies to reduce adolescent pregnancies is needed.

\section{List Of Abbreviations}

MMR; Maternal mortality ratio (per 100,000 live births); MDGs: Millennium Development Goals; WDI: World Development Indicators; WDI: World Development Indicators; Coef: coefficient; RE: Random Effect; FE: Fixed Effect; Obs: Observation; UCSF: Unidades Comunitarias de Salud Familiar; ECOS: Equipos Comunitarios de Salud; HEM: Hogar de Espera Materna;

\section{Declarations}

Ethics approval and consent to participate

This study was granted a waiver of review by the Institutional Review Board of Seoul Women's College of Nursing (No. SWCN-201407-HR-002). The need for informed consent was waivered by the Institutional Review Board of Seoul Women's College of Nursing

\section{Consent for publication}

Not applicable.

\section{Funding}

The authors report no financial or personal relationships with other people or organisations.

\section{Availability of data and materials}

The datasets used and analysed during the current study are available from the corresponding author

\section{Competing interests}


No potential conflict of interest was reported by the authors.

\section{Acknowledgements}

The authors would like to thank and acknowledge the work of the KOICA and Ministry of Health of El Salvador.

\section{Authors' contributions}

$\mathrm{CK}$ and $\mathrm{HY}$ conceived the study. CK led the analysis of all the data. HY reviewed the literature. All authors contributed to the drafting of the manuscript. All authors read and approved the final manuscript.

\section{References}

1. United Nations El Salvador. 3rd Report on the Progress of the Millennium Development Goals El Salvador. Government of El Salvador United Nations System in El Salvador, El Salvador; 2014.

2. The World Bank. World Development Indicators, 2018. Accessed 22. Dec 2019. http://datatopics.worldbank.org/world-development-indicators/user-guide.html

3. UNFPA. State of World Population. New York: UNFPA; 2005.

4. WHO, UNFPA. Pregnant Adolescents: Delivering on Global Promises of Hope. Geneva: WHO; 2006.

5. Doubova S, Guanais F, Pérez-Cuevas R, Canning D, Macinko J, Reich M. 2016. Attributes of patient-centered primary care associated with the public perception of good healthcare quality in Brazil, Colombia, Mexico and El Salvador. Health Policy and Planning. 2016; 33: 834-843. doi: 10.1093/heapol/czv139.

6. Padilla de Gil M. Contribution of the Central American and Caribbean obstetrics and gynecology societies to the prevention of unsafe abortion in the region. International Journal of Gynecology and Obstetrics. 2014; 126, S10S12. doi.org/10.1016/j.ijgo.2014.03.005

7. KOICA. Ex-Post Evaluation Report on Maternal and Child Health Projects in Four Latin American Countries. Seoul: KOICA; 2014.

8. Marroquín M. 2015. Mecanismos e incentivos para cubrir áreas desatendidas: Implementación de la estrategia de Equipos Comunitarios de Salud Familiar en El Salvador. El Salvador: Ministerio de Salud El Salvador; 2015

9. Ministerio de Salud. Redes Integrales e Integradas de los Servicios de Salud. El Salvador: Gobierno de El Salvador; 2014.

10. WHO. El Salvador Territorial community teams. Geneva: WHO; 2018.

11. Portillo J. Sistema Informatico para la Dispensarizacion de los Pacientes de los Equipos Communitarios de Salud Familiar del Ministerio de Salud. San Salvador: Universidad de El Salvador; 2015.

12. Rodríguez, M. Construyendo la esperanza Estrategias y recomendaciones en salud. El Salvador: Ministerio de Salud de El Salvador; 2009.

13. NINSAL. Lineamientos técnicos para el funcionamiento de los hogares de espera materna. El Salvador: Gobierno de El Salvador; 2017.

14. Lori J, Wadsworth A, Munro M, Rominski S. 2013. Promoting access: The use of maternity waiting homes to achieve safe motherhood. Midwifery. 2013;29:1095-1102. doi.org/10.1016/j.midw.2013.07.020

15. Chandramohan D, Cutts F, Chandra R. Effects of a maternity waiting home on adverse maternal outcomes and the validity of antenatal risk screening. International Journal of Gynecology \& Obstetrics. 1994; 46: 279-284.

16. Ruiz-Canela M, López-del Burgo C, Carlos S, Calatrava M, Osorio A, de Irala J. 2012. Familia, amigos y otras fuentes de información asociadas al inicio de las relaciones sexuales en adolescentes de El Salvador. Revista 
Panamerica Salud Publica. 2012; 31: 54-62.

17. Velázquez R, Pozo M. 2017. Aspectos epidemiológicos sobre adolescentes embarazadas en un área del municipio

El Salvador, Guantánamo. Revista Informacion Cientifica. 2017; 96: 346-354.

\section{Tables}

Table 1. MMR and other health indicators

\begin{tabular}{|c|c|c|c|c|c|c|c|c|c|c|c|c|}
\hline & \multicolumn{3}{|l|}{ MMR } & \multicolumn{3}{|c|}{ Fertility rate } & \multicolumn{3}{|c|}{ Adolescent fertility rate } & \multicolumn{3}{|c|}{$\begin{array}{l}\text { Health expenditure } \\
\text { (\% of GDP) }\end{array}$} \\
\hline & 1995 & 2015 & $\nabla$ & 1995 & 2015 & $\nabla$ & 1995 & 2015 & $\nabla$ & 2001 & 2015 & $\triangle$ \\
\hline $\begin{array}{l}\text { El } \\
\text { Salvador }\end{array}$ & 118 & 54 & $54.2 \%$ & 3.58 & 2.10 & $41.3 \%$ & 97.6 & 71.1 & $27.2 \%$ & 7.8 & 6.9 & -0.9 \\
\hline Guatemala & 173 & 88 & $49.1 \%$ & 5.09 & 3.03 & $40.5 \%$ & 122.6 & 74.0 & $39.7 \%$ & 6.7 & 5.7 & -1.0 \\
\hline Honduras & 166 & 129 & $22.3 \%$ & 4.64 & 2.51 & $46.0 \%$ & 121.5 & 73.6 & $39.5 \%$ & 5.9 & 7.6 & 1.7 \\
\hline Ecuador & 131 & 64 & $51.1 \%$ & 3.36 & 2.51 & $25.3 \%$ & 84.8 & 75.3 & $11.2 \%$ & 3.7 & 8.5 & 4.8 \\
\hline Paraguay & 147 & 132 & $10.2 \%$ & 4.11 & 2.51 & $38.9 \%$ & 92.1 & 57.5 & $37.6 \%$ & 5.5 & 7.8 & 2.3 \\
\hline Bolivia & 390 & 206 & $47.2 \%$ & 4.50 & 2.92 & $35.1 \%$ & 92.3 & 69.9 & $24.3 \%$ & 4.7 & 6.4 & 1.7 \\
\hline $\begin{array}{l}\text { Latin } \\
\text { America }\end{array}$ & 118 & 68 & $42.4 \%$ & 2.94 & 2.10 & $28.8 \%$ & 84.3 & 63.9 & $24.2 \%$ & 6.2 & 7.4 & 1.2 \\
\hline
\end{tabular}

Source: World Development Indicators

Table 2 Variables included in the empirical model of MMR

\begin{tabular}{|c|c|c|c|}
\hline & Variables & Explanation & Source \\
\hline Dep. Variable & MMR & Maternal mortality ratio (per 100,000 live births) & WDI \\
\hline \multirow{4}{*}{$\begin{array}{l}\text { Independent Variables } \\
\text { (Health Sector) }\end{array}$} & TFR & Total Fertility Rate (births per woman) & WDI \\
\hline & ATFR & Adolescent Fertility Rate (births per 1,000 women ages 15-19) & WDI \\
\hline & SKILL & Skilled Birth Attendance (\% of total) & WDI \\
\hline & HEALTH & Total health expenditure to GDP ratio (\%) & WDI \\
\hline \multirow{5}{*}{$\begin{array}{l}\text { Independent Variables } \\
\text { (Non-Health Sector) }\end{array}$} & GDPC & GDP per capita (dollars) & WDI \\
\hline & FSECOND & School enrollment, secondary, female (\% gross) & WDI \\
\hline & ELECTRIC & Access to electricity, rural (\% of rural population) & WDI \\
\hline & URBAN & Urban population (\% of total) & WDI \\
\hline & FPARLIA & Proportion of seats held by women in national parliaments (\%) & WDI \\
\hline
\end{tabular}

WDI: World Development Indicators 
Table 3. Regression results

\begin{tabular}{|c|c|c|c|c|c|c|c|}
\hline & & \multicolumn{2}{|c|}{ pooled OLS } & \multicolumn{2}{|c|}{ Panel regression (RE) } & \multicolumn{2}{|c|}{ Panel regression (FE) } \\
\hline \multicolumn{2}{|l|}{ Variables } & Coef. & t-value & Coef. & t-value & Coef. & t-value \\
\hline \multirow[t]{4}{*}{ Health Sector } & $\log (T F R)$ & $0.972^{\star \star}$ & 12.70 & -0.078 & -0.47 & -0.329 & -1.76 \\
\hline & $\log ($ ATFR) & $0.489^{* *}$ & 13.48 & $0.511^{\star *}$ & 6.12 & $0.482^{\star \star}$ & 4.50 \\
\hline & $\log (S K I L L)$ & -0.120 & -1.74 & -0.082 & -1.62 & $-0.182^{* *}$ & -2.90 \\
\hline & $\log (\mathrm{HEALTH})$ & $-0.162^{\star *}$ & -2.61 & -0.056 & -0.87 & -0.057 & -0.83 \\
\hline \multirow{12}{*}{$\begin{array}{l}\text { Non-Health } \\
\text { Sector }\end{array}$} & $\log (G D P C)$ & $-0.298^{\star *}$ & -10.75 & $-0.523^{\star *}$ & -6.11 & $-0.456^{\star *}$ & -3.94 \\
\hline & $\log ($ FSECOND) & -0.125 & -1.38 & -0.034 & -0.64 & -0.048 & -0.84 \\
\hline & $\log (E L E C T R I C)$ & $-0.098^{\star *}$ & -2.77 & $-0.050^{*}$ & -2.54 & -0.018 & -1.01 \\
\hline & $\log ($ URBAN) & $-0.152^{*}$ & -2.12 & -0.265 & -1.55 & -0.220 & -0.83 \\
\hline & $\log (\mathrm{FPARTICI})$ & 0.062 & 0.81 & -0.082 & -0.86 & -0.211 & -1.78 \\
\hline & $\log ($ FPARLIA) & $-0.111^{* *}$ & -3.75 & 0.012 & 0.47 & -0.004 & -0.14 \\
\hline & Constant & $4.210^{\star \star}$ & 8.69 & $5.338^{\star \star}$ & 6.59 & $5.989^{\star \star}$ & 5.10 \\
\hline & & \multicolumn{2}{|c|}{ N. obs $=982$} & \multicolumn{2}{|c|}{ N. obs $=982$} & \multicolumn{2}{|c|}{ N. obs $=982$} \\
\hline & & \multicolumn{2}{|c|}{$\mathrm{R}^{2}=0.857$} & \multicolumn{2}{|c|}{ N. groups $=143$} & \multicolumn{2}{|c|}{ N. groups $=143$} \\
\hline & & & & \multicolumn{2}{|c|}{$\mathrm{R}^{2}$ within $=0.521$} & \multicolumn{2}{|c|}{$\mathrm{R}^{2}$ within $=0.531$} \\
\hline & & & & \multicolumn{2}{|c|}{ between $=0.822$} & \multicolumn{2}{|c|}{ between $=0.789$} \\
\hline & & & & \multicolumn{2}{|c|}{ overall $=0.789$} & \multicolumn{2}{|c|}{ overall $=0.756$} \\
\hline
\end{tabular}

*Significant at $0.05 ; * \star$ Significant at 0.01

Table 4. Change in the MMR

\begin{tabular}{|llll|}
\hline & 2011 & 2012 & 2013 \\
\hline Prediction with fixed effect & 59.4 & 58.3 & 57.2 \\
\hline Yearly reduction of prediction & & 1.1 & 1.1 \\
Observed value & 60.0 & 57.0 & 55.0 \\
\hline Yearly reduction & & 2.0 & 3.0 \\
\hline MMR reduction not explained & & 0.9 & 1.9 \\
\hline
\end{tabular}


Table 5. El Salvador Nationwide HEM Number of Users (2013)

\begin{tabular}{|c|c|c|c|}
\hline & $\begin{array}{l}\text { Adolescent } \\
\text { up to } 19 \text { years old }\end{array}$ & $\begin{array}{l}\text { Adults } \\
\text { over } 20 \text { years old }\end{array}$ & Total \\
\hline Atiquizaya & 59 & 118 & 177 \\
\hline Corinto & 83 & 164 & 247 \\
\hline Suchitoto & 9 & 18 & 27 \\
\hline Cara Sucia & 26 & 52 & 78 \\
\hline Coatepeque & 74 & 111 & 185 \\
\hline Sonsonate & 101 & 243 & 344 \\
\hline La Palma & 64 & 144 & 208 \\
\hline Colón & 64 & 97 & 161 \\
\hline La Libertad & 23 & 33 & 56 \\
\hline San Juan Nonualco & 42 & 61 & 103 \\
\hline La Herradura & 31 & 44 & 75 \\
\hline Panchimalco & 22 & 31 & 53 \\
\hline San Gerardo & 17 & 38 & 55 \\
\hline Perquin & 120 & 234 & 354 \\
\hline Anamoros & 57 & 107 & 164 \\
\hline La Union & 121 & 179 & 300 \\
\hline Total & 913 & 1,674 & 2,587 \\
\hline
\end{tabular}

Source: KOICA

\section{Figures}




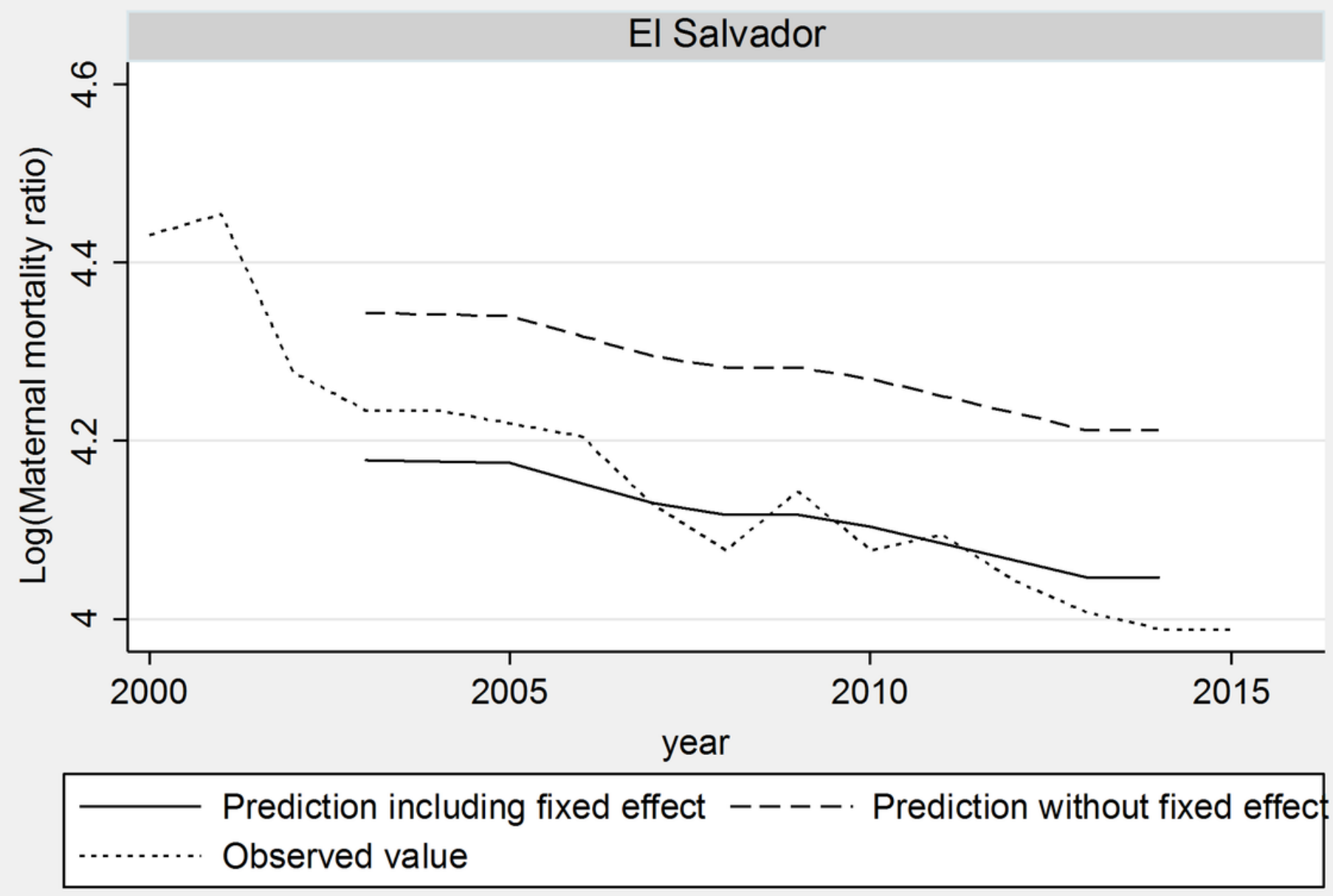

Graphs by Country Name

Figure 1

Maternal Mortality Ratio in El Salvador 